\title{
ITO Risks Preliminary Analysis Model of IT Outsourcing Corporations in China
}

\author{
Jiang Lingmin, Zhong Ruiqiong \\ School of Informatics, Guangdong University of Foreign Studies, 510420, China
}

\begin{abstract}
With the development of the computer technology and international specialization, a growing number of companies consider outsourcing as an effective method to improve the operation environment, reduce the cost, and enhance the efficiency. Despite of the many advantages comes with it, the risk in the outsourcing process should not be overlooked - for instance, the risk of invisible transactional cost escalation and unsatisfactory services from incompetent outsourcing suppliers. In this paper we propose a risk analysis model, which is based on factor analysis, for the ITO's in China. This model is also proven to be feasible and practical through an empirical analysis.
\end{abstract}

Index Terms - IT outsourcing, risk analysis, factor analysis, empirical analysis

\section{Introduction}

With the development of IT outsourcing, many experts and scholars, both demostic and international, have redirected their attention from the advantages of IT service outsourcing to the risk analysis of it. Among the numerous risk theorems that has been proposed in the area of IT service outsourcing, they mostly fall into two major categories. The first category is oriented by risk management theories and studies systematically the problems such as risk recognization, risk control, risk evaluation and risk management tools etc. The second category emphasizes in risk management and deals with more specific problems such as risk analysis, evaluation and precaution etc.

It is vital for the client to choose a competent supplier during IT service outsourcing process. Scholars both demostic and international have done great amount of research on the risk of IT service outsourcing most of which, however, are based on theoretical study and lack of practical risk analysis model. This paper proposes a factor-analysisbased risk evaluation model which may have practical value for IT service supplers in China.

\section{Index Design for IT Service Outsourcing Risk Evaluation System}

With all the advantages that come with IT service outsourcing such as appropriate allocation of resources, enhancment of entrepreneurial core competitiveness and reducing trading cost etc, there are certain risk as well, such as the product quality from the client, the mismatch of entrepreneurial cultures and prefessional experiences between vendor and client. Those potential risks may eventually affect the result of the outsourcing.

\subsection{Index selection of the risk evaluation system \\ Macroscopically speaking, industry clustering in}

outsourcing has emerged regionally in China due to intensive input. The development of service outsourcing is closely related with external economical, financial and political environment. Therefore it is necessory to include indexes which reflect effects from external environment.

Microscopically speaking, the indexes involved in financial statement are themselves very powerful in explaining entrepreneurial operating performance, analyzing manufacuring efficiency and predicting future development and value and so on. Moreover, these financial indexes are easy to be processed and have been studied and accepted for a long time, which guarantees their objectivity and accuracy.

In sum, the selection of indexes for risk evaluation system should consider both external and internal enviornments and cover macro- and microscopical factors to provide comprehensive risk evaluation service.

\subsection{Establishment of the risk evaluation system indexes}

Based on fore-mentioned considerations and previous experiences, 20 indexes, both financial and non-financal, are selected and explained as follows:

$\mathrm{x} 1$, policy guidence. The strength of support from policy, such as leagal tax avoidance, tax incentive etc.

$\mathrm{x} 2$, the rate of growth of production. This index describes the development trend of the outsourcing enterprise and its importance in local area.

$x 3$, density of enterprise. The total number of outsourcing enterprises in local area reflects the industrial clustering of such enterprises.

$\mathrm{X} 4$, the propotion of large-and-middle-sized enterprises.

$\mathrm{X} 5$, the service of the industrial park, namely, if this industrial park has been awarded certificate from the government.

$\mathrm{X} 6$, net assets income ratio. Net profit afer tax/Annual average balance of net assets $* 100 \%$. This index represents the returns on investment of the stock holders of this enterprise, which is also known as return on net worth or return on equity. With higher net assets income ratio, the enterprise makes more profits with owned capital.

$\mathrm{X} 7$, business profit. Business profit $=$ business income - business cost - business tax and additionals - sales cost management overhead - financial cost - assets impairment cost + net gain on change in fair value + net return on investment. This index provides a immediate information of the profitting ability of the enterprise.

$\mathrm{X} 8$, rate of return on sales $=$ net profit/operating revenue* $100 \%$, which measures the income levels of sales. 
$\mathrm{X} 9$, rate of return on total assets. (net profit + interest expense)/annual average assets balance * $100 \%$. This index reflects the enterprise's ability of making profit from its net assets, which is of great significance in evaluatting operating benefit of the enterprise. A high rate states an effective asset operation level.

X10, inventory turnover rate. Product sales cost/average inventory. A high turnover rate reflects a better ability of the enterprise to realization of assets inventories and to operate.

$\mathrm{X} 11$, asset-debt ratio. Net debt/net efficient assets $*$ $100 \%$. The reasonable value of this index falls in $60 \%$ to $70 \%$ and enterprises with a index value greater than $85 \%$ should be warned of high financial risk.

$\mathrm{X} 12$, liquidity ratio. This index equals to the final liquid assets assets / final current liabilities and measures the assets liquidity of the enterprises. It also reflects the short-term debt repaying ability.

$\mathrm{X} 13$, net profit increasing rate $=$ (net profit of this year - net profit of last year)/net profit last term * $100 \%$. It is a comprehensive measurement of the assests operation, management performance and profitability of the enterprise.

$\mathrm{X} 14$, net assets growth rate. (end of year asset beginning of year asset)/beginning of year asset $* 100 \%$. This index measures the asset keep value and add value and the potential of development of the enterprise.

$\mathrm{X} 15$, total asset growth rate. Total asset growth this year/beiginning of year total asset $* 100 \%$, which represents the speed of the expansion of the scale of operation.

$\mathrm{X} 16$, number of research center. More research centers usually means great demand of development and creative thinking.

X17, Amount of honor. This index describes the innovation achievement of the enterprise.

X18, qualification certification. To gain such certification is a good way for the enterprise to enhance management level and product quality. It provides a measurement of the enterprise from the management perspective.

X19, enterpriser's qualities. This index is calculated from the education level and experience of the quantized of the major administrators. The enterpriser's qualities directly influence its decision making, program planning and development.

$\mathrm{X} 20$, areas covered by the enterprise's branches. This index shows the amount of impact of this ernterprise.

\section{The Model of IT Service Outsourcing Risk Analysis}

\subsection{Selection of research objects and specimen}

The objects of this research are information technique outsourcing (ITO) enterprises in China. 31 listed ITO companies are selected from service outsourcing industrial parks in 10 cities of China, such as Shenzheng, Beijing and Jinan etc. Listed companies have several advantages over the unlisted ones. They are supervised by the financial supervision commission and stock exchange and their financial reports are public and checking visa after the accounting. Moreover, the installation environments of the industrial parks which those enterprises belong to can be easily accessed on the outsourcing website of the local government.

\subsection{Mathematical Model}

Factor analysis extracts a few synthesized factors out of the observed variables to explain the original data. The relative weight of each factor are based on the internal structural relation between them, which is immune to subjective influence. Moreover, the information overlap among the selected indexes are small enough for easy comparison. Therefore, this paper builds a IT service outsourcing risk evaluation model based on the factor analysis method.

Assume $\mathrm{P}$ original random variables (RV), X1, X2, $\mathrm{X} 3, \ldots \mathrm{Xp}$, each with a mean value (or central moment) of 0 and unit variance. Now express the set of original RVs as the linear combination of $\mathrm{K}(\mathrm{K}<\mathrm{P})$ factors $\mathrm{f} 1, \mathrm{f} 2, \mathrm{f} 3, \ldots \mathrm{fk}$, i.e.

$$
\left\{\begin{array}{c}
x_{1}=a_{11} f_{1}+a_{12} f_{2}+a_{13} f_{3}+\cdots+a_{1 k} f_{k}+\varepsilon_{1} \\
x_{2}=a_{21} f_{1}+a_{22} f_{2}+a_{23} f_{3}+\cdots+a_{2 k} f_{k}+\varepsilon_{2} \\
\cdots \cdots \\
x_{p}=a_{p 1} f_{1}+a_{p 2} f_{2}+a_{p 3} f_{3}+\cdots+a_{p k} f_{k}+\varepsilon_{p}
\end{array}\right.
$$

The establishment of the factor analysis model consists of several steps. First, set up the indexes system and the original matrix. Ensure that all indexes of the same direction based on the sample data standardization processing, we have Eq. 1 and 2, from which the standardization matrix $\mathrm{R}^{\prime}$ and the coefficient matrix $\mathrm{R}$ are derived.

$$
\begin{gathered}
X_{i j}=\frac{X_{i j}-\overline{X_{j}}}{\sqrt{S_{j}}}(\mathrm{i}=1,2, \ldots, \mathrm{p} ; \mathrm{j}=1,2, \ldots, \mathrm{n}) \\
\overline{X_{j}}=\frac{1}{n} \sum_{j-1}^{n} X_{i j}, S_{j}=\frac{1}{n-1} \sum_{j-1}^{n}\left(X_{i j}-\overline{X_{j}}\right)(\mathrm{i}=1,2, \ldots, \mathrm{p})
\end{gathered}
$$

Second, solve the eigenvalue $\lambda \mathrm{i}$ from equation $|\mathrm{R}-\lambda \mathrm{E}|=0$. Given $\lambda 1 \geq \lambda 2 \geq \ldots \geq \lambda \mathrm{p} \geq 0$, the number of common factors $\mathrm{P}$ can be calculated according to the accumulated variance contribution rate. The accumulated variance contribution rate of the first $\mathrm{K}$ factors are: Eq. (3)

$$
a_{k}=\sum_{i=1}^{k} S_{i}^{2} / P=\sum_{i-1}^{k} \lambda_{i} / \sum_{i=1}^{p} \lambda_{i}
$$

Using the orthogonal or oblique rotation method orthogonal or oblique factor load matrix, based on the orthogonal or oblique factor loading matrix of the absolute value of correlation coefficient, identify and name public factor.

Finally, calculate the score of common factor and integrated score. The value of the jth factor on ith specimen is shown to be: , where As are the factor coefficient between the jth factor and each of the $p$ original variable, respectively. It is easy to see that the process of factor analysis is the linear combination of the original variables. The scores of the common is the weighted summation of each variable where the weight represents the importance of the variable, i.e., Eq. (4) 


$$
F_{j}=\overline{W_{j 1}} X_{1}+\overline{W_{j 2}} X_{2}+\ldots \ldots+\overline{W_{j p}} X_{p}
$$

\section{Empirical Analysis of the Risk Evaluation Model of IT Service Outsourcing in China}

\subsection{The selection of data}

We selected the data of 31 service outsourcing enterprise as the original data. These datas are divided into 3 categories, the external environmental data of the enterprise, the internal financial data of the enterprise and internal non-financial data.

\subsubsection{The external environmental data of the sample enterprise}

Sample enterprises are selected from 10 different regions, they are Beijing, Shanghai, Shenzhen, Xiamen, Hefei, Changchun, Shenyang, Jinan, Xi'an and Hangzhou.

We use the following four quantifiable indexes:

1 , the number of supportive policies that related to IT service outsourcing in the target area.

2 , increase rate of the value of IT service outsourcing industry in the target area $=$ the increase of the value of this industry between 2011 and 2012 / the value of this industry at the beginning of $2011 * 100 \%$.

3 , the density of enterprise is the total number of IT outsourcing enterprise in the area of the sample enterprise.

4 , the ratio of large and midium-sized enterprises in the target region.

5 , the level of service of the industrial park in which the sample enterprise is in is assigned according to national standard on the scale from 1 to 10 , with higher score comes better service.

\subsubsection{Internal Financial data of the sample enterprise}

The finanical index system has developed into a complete system which has high public trust and poplularizing rate. Finaical data directly reflects the operating situation of the enterprise. It shows the profit and expansion rate of the enterprise. Therefore when evaluating the internal financial situation of the enterprise, we choose the most representative indexes to describe the profiability, operation capacity, payment ability and progressive ability.

\subsubsection{Internal non-financial data of the sample enterprise}

The creativity and development of the IT service supplier are also important. However they cannot be concluded from the financial indexes. Therefore we need the following non-financial indexes to quantify the creativity and development.

1 , number of $\mathrm{R} \& \mathrm{D}$ center.

2 , number of national, provincial and city-level honors.

3 , number of qualification certification. Various of international certification obtained by the enterprise, such as CMM, CMMI and ISO.

4 , quality of the entrepreneur. This index is computed from the academic certificates and experience of the highlevel administrators of the enterprise. Quality of the entrepreneur $=$ (number of people with B.S. degree $* 1+$ number of people with M.S. degree $* 2+$ number of people with $\mathrm{Ph} . \mathrm{D}$. degree $* 3+$ number of people with special experience (such as previous experience of successful operation and oversea education) * 1)/Total number of highlevel administrator.

5 , number of regions that are covered by branches of the enterprise. The total number of branches and agencies of the sample enterprise.

\subsection{Index refinement}

We first strip away those enterprise without complete data. After which, we use SPSS 17.0 for Windows to process the stripped data and delete abnormal samples to protect the integrity of data. Finally the following 29 enterprises are chosen as the sample space: Neusoft Corporation; Insigma Technology Co.; Shandong Inspur software Co.,Ltd.; Hundsun Technologies Inc.; Shanghai Hyron Software Co., Ltd.; China National Software \& Service Company Limited; Beijing Ufsoft Co.,Ltd.; Sunyard System Engineering Co.,Ltd.; Shanghai Baosight Software Co.,Ltd.; YGsoft inc.; QiMing Information Technology Co.; Xiamen 35.com Technology Co., Ltd.; Anhui Wantong Technology Co.,Ltd.; Anhui Ustc Iflytek Co.,Ltd; Beijing SuperMap Software Co.,Ltd.; Shenzhen Das Intellitech Co.,Ltd.; DHC Software CO.,LTD.; Hangzhou New Century Information Technology Co.,Ltd.; Beijing Join-cheer Software Co.,Ltd.; Beijing Teamsun Technology Co.,Ltd.: Shenzhen Kingdom Technology Co.,Ltd.: Shenzhen Tianyuan Dic Information Technology Co., Ltd., Enjoyor Co.,Ltd., Beijing Lanxum Technology Co.,ltd.; Guomai Technologies,Inc.; Shenzhen InfoTech Technologies Co.,ltd.; Beijing Surekam Technology Co.,ltd.; Hanwang Technology Co.,Ltd.

After getting rid of indexes with low relevance, 13 indexes are selected. $\mathrm{x} 1$, policy guidance; $\mathrm{x} 2$, density of enterprise; $\mathrm{x} 3$, the propotion of large-and-middle-sized enterprises; $\mathrm{x} 4$, the service of the industrial park; $\mathrm{x} 5$, net assets income ratio; $x 6$, business profit; $x 7$, rate of return on sales; $\mathrm{x} 8$, rate of return on total assets; $\mathrm{x} 9$, asset-debt ratio; $\mathrm{x} 10$, net profit increasing rate; $\mathrm{x} 11$, total asset growth rate; $\mathrm{x} 12$, number of research center; $\mathrm{x} 13$, qualification certification.

\subsection{Process analysis}

\subsubsection{KMO examination and joint degree examination}

$\mathrm{KMO}$ (Kaiser-Meyer-Olkin) statistic s used to compare ariables between simple correlation coefficient and partial correlation coefficient index, thevalues between 0 and 1 , when the simple correlation coefficient square allvariables are far more than partial correlation coefficient and time, KMO value close to $1, \mathrm{KMO}$ value is close to 1 , means that the correlation between variables the stronger the will, the original variables are more suitable for factor analysis; when the simple correlation coefficients of allvariables and close to $0, \mathrm{KMO}$ value close to $0, \mathrm{KMO}$ value is close to 0 , means that the correlation between variables is weak, the originalvariables is not suitable for factor analysis.

The KMO value of the enterprises' indexes is chosen to be 0.638 , which is greater than 0.5 and thus is suitable for factor analysis. 
The joint degree of the variables is the common choice for measuring the effect of factor analysis. For a specific original variable, its joint degree is defined to be the sum of squares of the load of all its factor. It reflects the ability of all the common factors in interpreting the original variable and takes the value between 0 and 1 . A value more close to 1 represents a higher ability of interpretation. Generally speaking, only when the values of joint degree of all index variable is greater than 0.7 is the index data suitable for factor analysis, which is the case of this paper.

\subsubsection{Determine the number of common factors}

Application of principal component method of factor extraction. According to the "variance contribution rate" and "the cumulative contribution rate", each of the first four common factors explains $30.194 \%, 24.084 \%, 15.827 \%$ and $10.761 \%$ of the total variance, respectively, and $80.866 \%$ in total. This also qualifies these four factors as common factors.

\subsubsection{Rotated factor loading matrix, determine the common factors}

Given the four common factors, we use SPSS software to obtain factor loading matrix. By using the orthogonal rotation method on the results of the initialrotated factor loading matrix can be seen, factor loading appear to have extrem values, each of which represents clear economical siginificance. In factor $1, x 5, x 6, x 8, x 10$ and $x 11$ have great absolute values and represent the operation ability (F1). In factor 2, x1, x2, x3 and x4 have great absolute values and represent the regional environmental index (F2). In factor 3, $\mathrm{x} 12$ and $\mathrm{x} 13$ have great absolute values and represent quality of the enterprise index (F3). In factor 4, x7 and $\mathrm{x} 9$ have great absolute values and represent profit and loss (F4).

\subsubsection{Calculation of the factor scores and final score}

To conduct a comprehensive evaluation on these 29 IT service outsourcing suppliers, one nedd to caculate the score of the 4 common factors. We use regression method in this paper to get the following factor scoreing function:

$$
\begin{aligned}
\mathrm{F} 1= & 0.018 \times 1+0.03 \times 2-0.036 \times 3-0.028 \times 4+0.262 \times 5 \\
& +0.227 \times 6+0.082 \times 7+0.17 \times 8+0.153 \times 9+0.258 \times 10 \\
& +0.249 \times 11+0.006 \times 12-0.033 \times 13 \\
\mathrm{~F} 2= & 0.197 \times 1+0.324 \times 2+0.292 \times 3+0.302 \times 4+0.047 \times 5 \\
& -0.028 \times 6-0.057 \times 7+0.046 \times 8+0.031 \times 9-0.021 \times 10 \\
& -0.051 \times 11-0.057 \times 12-0.04 \times 13 \\
\mathrm{~F} 3= & 0.181 \times 1-0.053 \times 2-0.08 \times 3-0.061 \times 4+0.058 \times 5 \\
& +0.203 \times 6+0.018 \times 7-0.004 \times 8+0.025 \times 9-0.104 \times 10 \\
& -0.122 \times 11+0.41 \times 12+0.421 \times 13 \\
\mathrm{~F} 4= & 0.027 \times 1-0.109 \times 2-0.053 \times 3+0.046 \times 4-0.093 \times 5 \\
& -0.126 \times 6+0.412 \times 7+0.412 \times 8+0.202 \times 9-0.095 \times 10 \\
& +0.103 \times 11-0.01 \times 12+0 \times 13
\end{aligned}
$$

The relevance coefficient between these four common factors is calculated to be 0 by using the SPSS software. This means that the common factors are independent of each other and their selection is reasonable. By assigning the variance contribution rate of the four rotated common factors as the weight, the final score and ranking can be calculated as follows. From Eq. (5) the final score of the 29 enterprises can be derived.

$$
\mathrm{F}=(30.194 \mathrm{~F} 1+24.084 \mathrm{~F} 2+15.827 \mathrm{~F} 3+10.761 \mathrm{~F} 4) / 80.866
$$

\subsection{Comprehensive analysis}

The top enterprises in the ranking are: Neusoft Corporation; Dhc Software Co.,ltd.; Insigma Technology Co.,ltd; Beijing Teamsun Technology Co., Ltd.; Shanghai Baosight Software Co.,Ltd.; Yonyou Software Co., Ltd.; Beijing Lanxum Technology Co.,ltd.; YGSOFT INC.; Beijing Join-cheer Software Co.,Ltd; Beijing Supermap Software Co.,Ltd.; Sunyard System Engineering Co.,Ltd.; Shanghai Hyron Software Co.,Ltd.; QiMing Information Technology Co.,Ltd.; Hundsun Technologies Inc.; Shenzhen Tianyuan Dic Information Technology Co., Ltd. According to the data from Chinese service outsourcing web sites and the website of the enterprise, these 15 enterprises provided their clients with satisfactory service in the past three to five years. All of them are developing fast and share a reputation in the industry. Moreover, all 15 enterprises are Top 100 software enterprises, some of them are the China service outsourcing ten leading enterprises, 100 Chinese service outsourcing enterprises, national key software enterprise innovation, ten innovation of software enterprises, software industry leader, demonstration enterprises etc. In addition, these enterprises are all local leading companies which generate huge driving force for regional economy. Such IT service suppliers provide their clients with higher efficiency, optimized management, symetric information, exciting innovations and lower risks.

In comparison, the number $1,3,7,11,12$ and 13 enterprises in our ranking are respectively ranked number 2,6,12,26,29 and 39 in the list of top 50 service outsourcing companies in China in 2011. The consistency of ranking verifies the reliability of our risk evaluation model.

\section{Conclusions}

Based on the proposed model, the risk in IT service outsourcing reduces to four major categories, the operating ability, profit and loss, enterprise quality and the regional environmental situation of the IT service supplier. This model involves many aspects of the target enterprise and provides good reference for clients to choose IT suppliers. However, because of the invisible of services, this model can only give rise to a preliminary risk analysis.

\section{References}

[1] YUAN Xin. Service Outsourcing: Concept, Essence and Effect. International Economics and Trade Research, 2010(9): 10-15.

[2] YANG Bo, YIN Guopeng. Study on Chinese IT Services Vendor's Capability in Offshore Outsourcing.Chinese Journal of Management, 2010(2): 199-203.

[3] Ning Lianju, Li Meng. Evaluation model for large and medium sized industrial enterprises' technological innovation capability based on factor analysis method. Science Research Management, 2011(3): 51-58.

[4] LIU Yan1. The Determ inants of Developing Countries. Competitiveness to Undertake Offshore Service Outsourcing. Economic Survey, 2010(1):42-45.

[5] WANG Jian-jun, HE Ping. Intellectual Development and Emerging Trends of Information Technology Outsourcing Research. Journal of Industrial Engineering and Engineering Management, 2013(4):44-53. 